\title{
Chemoradioimmunotherapy of inoperable stage III non-small cell lung cancer: immunological rationale and current clinical trials establishing a novel multimodal strategy
}

\author{
Lukas Käsmann ${ }^{1,2,3+}$, Chukwuka Eze ${ }^{1 *+}$ (D), Julian Taugner ${ }^{1}$, Olarn Roengvoraphoj ${ }^{1}$, Maurice Dantes ${ }^{1}$, \\ Nina-Sophie Schmidt-Hegemann', Sanziana Schiopu ${ }^{2,4}$, Claus Belka ${ }^{1,2,3}$ and Farkhad Manapov $v^{1,2}$
}

\begin{abstract}
Immune-checkpoint inhibitors $(\mathrm{ICI})$ have dramatically changed the landscape of lung cancer treatment. Preclinical studies investigating combination of $\mathrm{ICl}$ with radiation show a synergistic improvement of tumor control probability and have resulted in the development of novel therapeutic strategies. For advanced nonsmall cell lung cancer (NSCLC), targeting immune checkpoint pathways has proven to be less toxic with more durable treatment response than conventional chemotherapy. In inoperable Stage III NSCLC, consolidation immune checkpoint inhibition with the PD-L1 inhibitor durvalumab after completion of concurrent platinumbased chemoradiotherapy resulted in remarkable improvement of progression-free and overall survival. This new tri-modal therapy has become a new treatment standard. Development of predictive biomarkers and improvement of patient selection and monitoring is the next step in order to identify patients most likely to derive maximal benefit from this new multimodal approach. In this review, we discuss the immunological rationale and current trials investigating chemoradioimmunotherapy for inoperable stage III NSCLC.
\end{abstract}

Keywords: Non-small cell lung cancer, Chemoradioimmunotherapy, Multimodal treatment, Immunotherapy

\section{Introduction}

Stage III non-small cell lung cancer (NSCLC) represents a very heterogeneous disease in terms of patient and tumour characteristics [1-5]. An interdisciplinary approach is necessary to define multimodal treatment strategies based on patients' condition and disease extension [6]. The majority of these patients are inoperable and multimodal therapy is considered as the cornerstone of treatment [7-10]. Historically,

\footnotetext{
* Correspondence: Chukwuka.Eze@med.uni-muenchen.de

†Lukas Käsmann and Chukwuka Eze contributed equally to this work.

'Department of Radiation Oncology, University Hospital, LMU Munich, Marchioninistrasse 15, 81377 Munich, Germany

Full list of author information is available at the end of the article
}

administering platinum-based chemotherapy sequentially or concurrently to thoracic irradiation resulted in a modest improvement of local control, metastasis-free and overall survival compared to radiation alone [11]. As a result of the ground-breaking phase III PACIFIC trial, PD-L1 inhibition with durvalumab after completion of platinum-based concurrent chemoradiotherapy (CRT) which demonstrated historically unprecedented long-term patient outcome is the new standard of care in inoperable stage III NSCLC [8].

Over the last couple of years, immune checkpoint inhibition (ICI) has become an established antitumor treatment in non-driver mutated advanced NSCLC. In 2015, the first PD1 inhibitor (nivolumab) was approved by the U.S. Food and

(c) The Author(s). 2020 Open Access This article is licensed under a Creative Commons Attribution 4.0 International License, which permits use, sharing, adaptation, distribution and reproduction in any medium or format, as long as you give appropriate credit to the original author(s) and the source, provide a link to the Creative Commons licence, and indicate if changes were made. The images or other third party material in this article are included in the article's Creative Commons licence, unless indicated otherwise in a credit line to the material. If material is not included in the article's Creative Commons licence and your intended use is not permitted by statutory regulation or exceeds the permitted use, you will need to obtain permission directly from the copyright holder. To view a copy of this licence, visit http://creativecommons.org/licenses/by/4.0/ The Creative Commons Public Domain Dedication waiver (http://creativecommons.org/publicdomain/zero/1.0/) applies to the data made available in this article, unless otherwise stated in a credit line to the data. 
Drug Administration (FDA) for previously treated advanced or metastatic squamous and non-squamous NSCLC $[12,13]$. Subsequently, a combination of pembrolizumab with different chemotherapy regimens (KEYNOTE-189 and 407 trials) demonstrated a further significant improvement of patient survival irrespective of tumour cell PD-L1 status compared to conventional chemotherapy alone [14, 15].

A growing body of evidence from preclinical studies suggest a combination of ICI and radiation as a potential opportunity to achieve a synergistic anti-tumour effect [16]. In this review, we summarise the preclinical data emphasising the rationale on combining chemo-, radioand immunotherapy, discuss the results of the current studies concerning this trimodal approach in stage III NSCLC, and reveal future perspectives as well as challenges of this novel multimodal treatment strategy.

\section{Preclinical rationale of combining immune check-point inhibition with chemo- and radiotherapy}

For decades, radiotherapy (RT) has been established as an effective local treatment modality. The principal target of ionising radiation is DNA, leading to a potential and fatal cell death [17]. Radiation-induced DNA damage include base damage, single strand breaks, double strand breaks of varying complexity and DNA crosslinks which occur by direct ionisation or indirectly by free oxygen radicals [18]. DNA repair mechanisms could resolve radiation-induced damage in normal cells. However, tumour cells have limited repair capacity and may undergo cell death by radiation-induced cell stress [17]. As a result, regression or complete remission of the irradiated tumour can be observed.

Increasing evidence also shows that RT influences tumour lesions outside the irradiated field. This phenomenon was described as the abscopal effect and has been observed for decades, but knowledge and understanding of the underlying mechanisms still remain very limited [19-22]. In 2004, Demaria et al. revealed that the abscopal effect is an immune-modulating effect of RT using a syngeneic mammary cancer model [23] (see Fig. 1). Since then, several preclinical studies have demonstrated that RT induces immunomodulatory

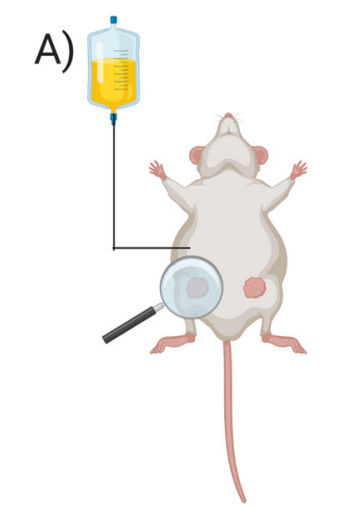

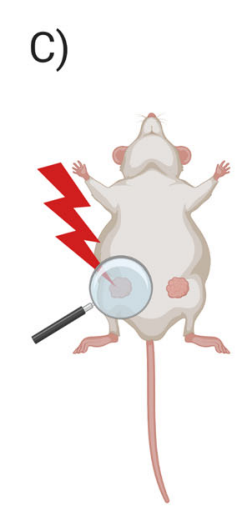

E)

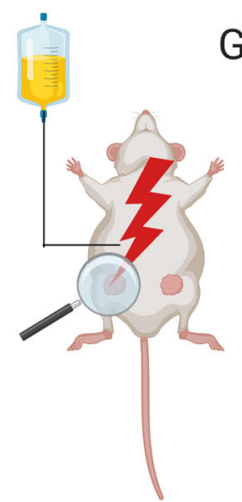

D)

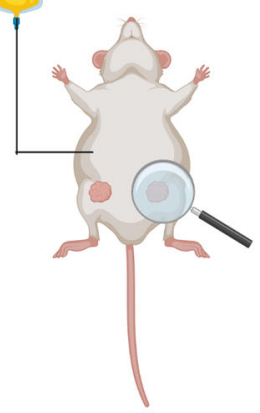

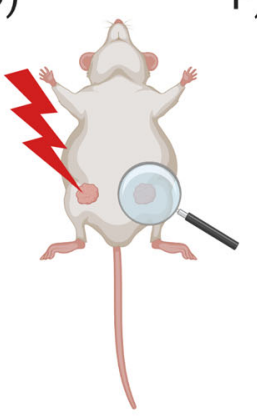

F)

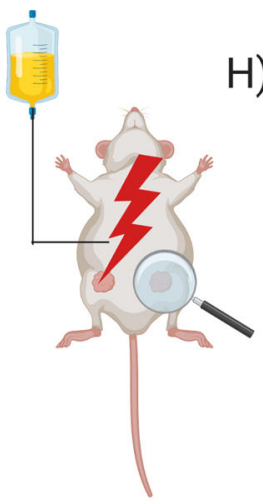

G)

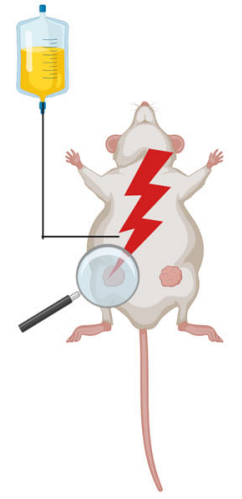

T cell deficient
H)

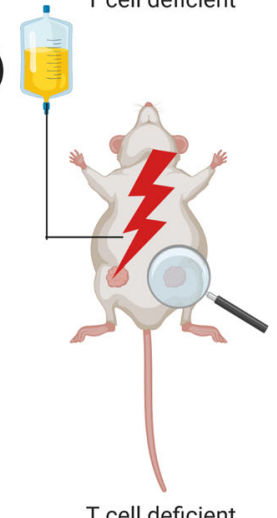

Fig. 1 Abscopal effect in preclinical model adapted from Demaria et al. [18]: Mice bearing a syngeneic mammary carcinoma (67NR) in both flanks were treated with growth factor Flt3-Ligand (Flt3-L) or local radiation therapy to one of the two tumors or combined treatment. The Flt3-L was used to enhance the number of available dendritic cells. Administering Flt3-L had no effect on tumor growth delay (a, b). RT alone led to tumor growth delay of the irradiated tumor $(\mathbf{c}, \mathbf{d})$. Combination treatment resulted in tumor growth delay in both flanks (e, $\mathbf{f})$ in contrast to $\mathbf{T}$ cell deficient mice where no tumor growth delay of nonirradiated tumor was observed $(\mathbf{g}, \mathbf{h})$ 
changes in the tumour microenvironment (TME), supporting a synergistic potential of radioimmunotherapy [24-29] (see Fig. 2). Combining RT with immune checkpoint inhibition may enhance local and systemic immune-mediated effects and trigger abscopal phenomena. Several mechanisms of radiation-induced immune-modulation have been identified (see Fig. 3) such as a radiation-induced alteration of tumour immunogenicity, generation of pro-inflammatory cytokines and local infiltration of effector cells. Increased major histocompatibility complex (MHC)-I expression after irradiation has been detected in lung cancer, which may lead to enhanced antigen presentation to immune effector cells such as dendritic cells or CD8+ T-lymphocytes [29-31]. Furthermore, irradiation leads to an upregulation of tumour cell PD-L1 expression in lung cancer, which interestingly appears to be CD8+ T-cell-dependent [32-34]. RT also increases natural killer group 2 member D (NKG2D) ligands in NSCLC which aids in tumour cell killing by interacting with NKG2D receptors on NK, NKT and $\gamma \delta$ T cells [35, 36]. In addition, $\mathrm{RT}$ has been shown to influence $\mathrm{T}$ cell priming and activation of antigen-presenting cells such as dendritic cells (DCs) in melanoma mouse model [37]. Thoracic irradiation increases the production of inflammatory cytokines in the lung such as tumour necrosis factor (TNF), interleukin (IL)- $1 \alpha$, and IL- 6 in vitro and may be associated with the abscopal effect of tumour response outside the radiation field [38, 39]. Furthermore, RT may play an essential part by the generation of tumour-derived antigens including neoantigens which could be recognised by antigenpresenting cells such as DCs and macrophages. Three immunogenic components are essential for radiationinduced immunogenic cell death (ICD), namely calreticulin, release of high mobility group box 1 (HMGB1) protein and adenosine-5' -triphosphate (ATP) [40]. Importantly, the release of pro-inflammatory cytokines (see Table 1) together with the radiation-induced change of the TME as well as angiogenesis result in the infiltration of activated CD8+ T cells $[42,43]$ which have been known to facilitate local and distant immune effects of RT [44, 45].

Besides the immunomodulatory effects of RT, chemotherapy has been found to contribute to tumour immunogenicity and tumour immune response [25, 46, 47].

Platinum compounds (cisplatin/carboplatin), etoposide, vinorelbine, pemetrexed and paclitaxel are the most frequently administered systemic agents in NSCLC $[1,3]$. Despite their established immunosuppressive effects due

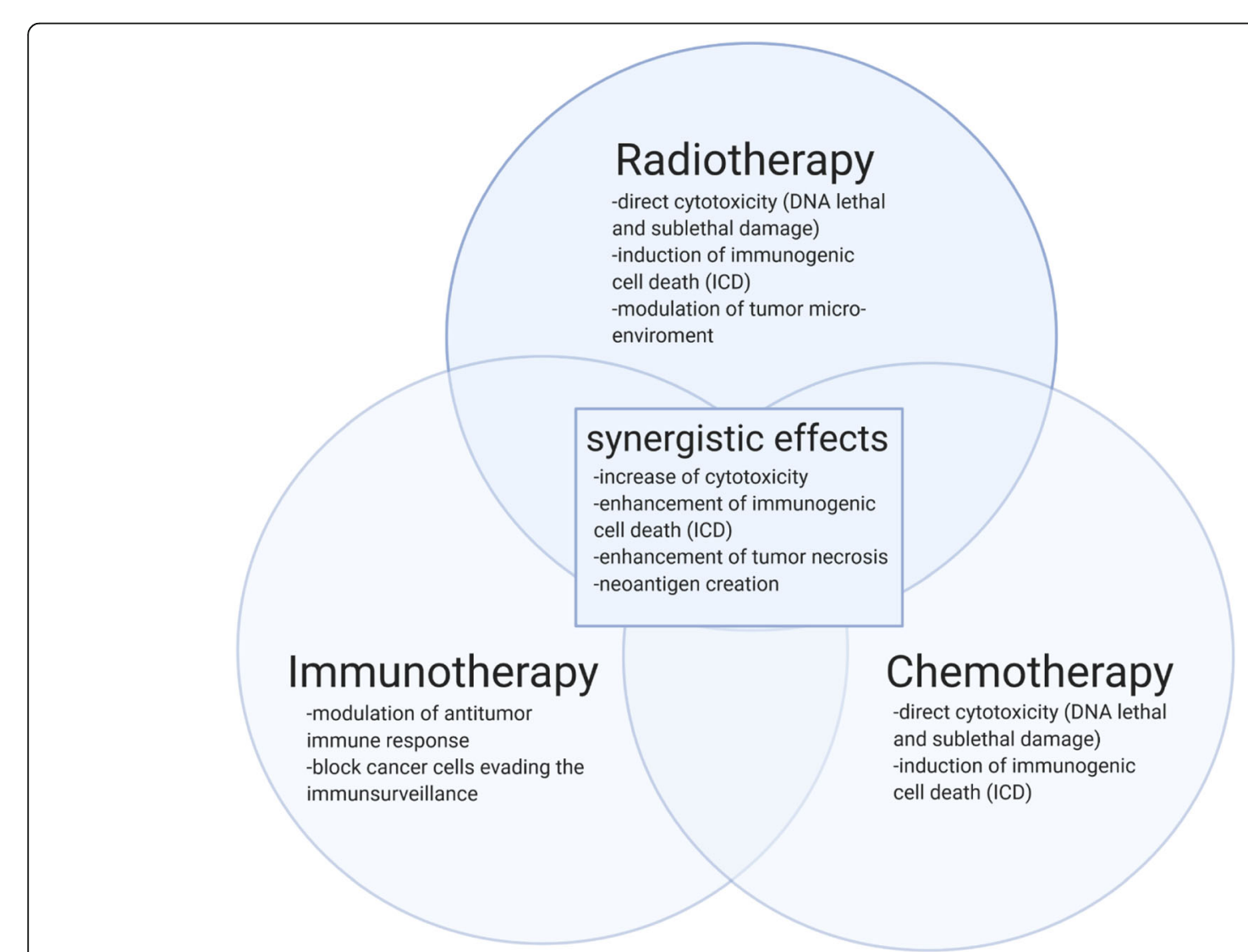

Fig. 2 Potential synergistic effects of chemo-, radio- and immunotherapy combinations 


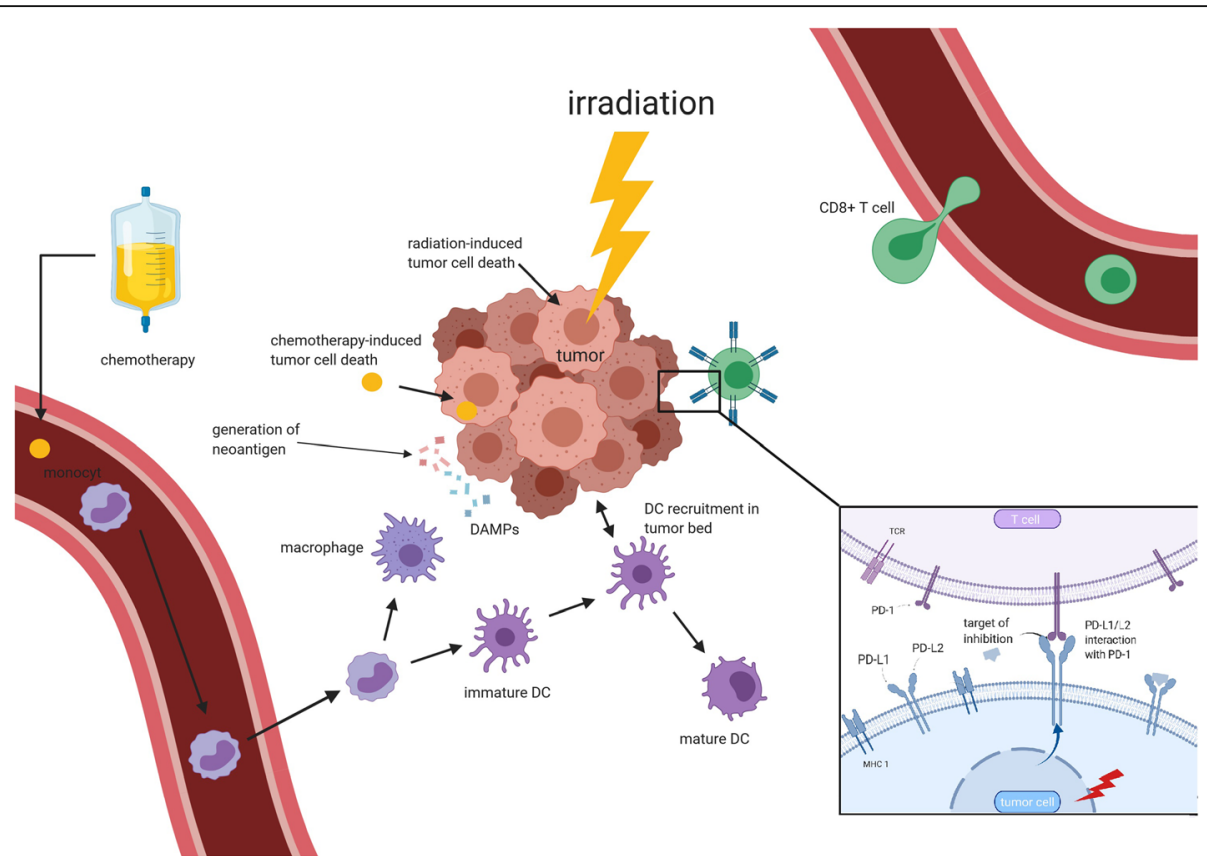

Fig. 3 Schematic view of synergistic interactions of chemo-, radio- and immunotherapy at irradiation site adapted from Lauber et al. [17]

to bone marrow suppression, immunoregulatory function which may contribute to antitumoral effects has been postulated [46]. Nowadays, it is hypothesised that conventional chemotherapy can promote tumour immunity due to the modulation of antitumor $\mathrm{T}$ cell response through increasing tumour antigenicity, inducing ICD, disrupting immune suppressive pathways and enhancing effector Tcell response.

Platinum compounds are the most studied anticancer agents and still represent the backbone of cancer treatment. Several mechanisms have been identified which show that platinum compounds such as cisplatin could modulate the immune system by the release of tumour antigens and the emission of danger-associated molecular patterns (DAMP) in the TME (see Table 1), upregulation of MHC class I expression, promoting recruitment and proliferation of effector cells, upregulation of cytotoxic effectors and downregulation of the immunosuppressive microenvironment $[25,47,48]$. As a result of the synergistic pathways of platinum compounds with irradiation and radio-sensitising effects, platinum-based chemotherapy appears to be a highly promising candidate of multimodal treatment based on preclinical data $[25,49,50]$. Based on the findings in breast cancer by Golden et al., ICD is produced dosedependent by irradiation and could be enhanced by the combination of platinum compounds in vitro [40].

Etoposide is a chemotherapeutic agent that inhibits DNA topoisomerase II with resultant DNA strand breaks and induction of cytotoxic and apoptotic cell death [51]. Importantly, etoposide is relatively cell cycle specific, and it affects cells in the S and G2 phases of cell division.

The immunosuppressive property of etoposide is well known due to myelosuppression; however, its immunomodulatory function is not fully understood. Johnson et al. found that etoposide causes apoptosis of activated, but not resting lymphocytes in vitro and indirectly

Table 1 Potential biomarkers of immunogenic cell death (ICD) adapted from Käsmann et al. [41]

\begin{tabular}{|c|c|}
\hline Parameter & Molecular determinants \\
\hline Cancer cell-associated pro-tumorigenic cytokines & IL1, IL10, IL6, IL33, TGF- $\beta$, VEGF, VEFGC, IDO enzyme, CXCL12, IL18 \\
\hline Immune cell-associated pro-tumorigenic cytokines & IL10, IDO enzyme, TGF- $\beta$, IL4, IL5, IL13, TNFa, M-CSF, GM-CSF, IL26, CXCI5, CCL7 \\
\hline $\begin{array}{l}\text { Danger signals (cell surface marker, cytokines/ } \\
\text { chemokines) }\end{array}$ & HMGB1, HSP70, antibodies against calreticulin/HSP90 \\
\hline $\begin{array}{l}\text { Cancer cell-associated viral response-like chemokine } \\
\text { signature }\end{array}$ & IFN- $a$, IFN- $\beta$, IFN- $\gamma$, CXCL9, CXCL10, CXCL1, CCL2 \\
\hline $\begin{array}{l}\text { Immune cell-associated anti-tumorigenic cytokines or } \\
\text { chemokines }\end{array}$ & $\begin{array}{l}\text { IL1B, IL12p70, IL15, IFNG, IL22, IL23, IL17A, IL2, CCL1, CXCL2, CCL4, CCL5, CCL8, CXCL11 } \\
\text { CCL12, CCL13, CXCL13, CXCL16, CCL17, CCL19, CCL22, CCL23, CCL24, CCL26 }\end{array}$ \\
\hline
\end{tabular}


suppresses inflammatory cytokine levels [52]. These findings go along with previous reports $[53,54]$ which highly question the role of etoposide in combined treatment approaches with immune checkpoint inhibition.

Vinorelbine is a semi-synthetic vinca-alkaloid which represents a spindle poison. The therapeutic mechanism of action is to interfere with the polymerisation of tubulin, a protein responsible for building the microtubule system which appears during cell division. The immunomodulatory properties of vinorelbine are rather unknown. However, vinorelbine in combination with platinum-based chemotherapy has been investigated with potential enhancement of immunogenicity of lung cancer cells. Gameiro et al. showed that MHC class I expression increased more than $50 \%$ in $\mathrm{H} 1703$ and $\mathrm{A} 549$ lung cancer cell lines after treatment with cisplatin/vinorelbine combination [47].

Pemetrexed is an antifolate which inhibits multiple targets involved in folate metabolism. Currently, it is mainly administered in non-squamous NSCLC. In colorectal cancer, pemetrexed treatment alone increased $\mathrm{T}$ cell activation in a mouse model, and induced ICD [55]. As a result, pemetrexed is a highly interesting candidate for combination treatment with radiotherapy and immunotherapy due to the increased activity and infiltration of $\mathrm{T}$ cells along with the modulation of the innate immune pathways caused by pemetrexed.

Paclitaxel is naturally produced in the bark and needles of Taxus brevifolia and represents a tricyclic diterpenoid compound. In contrast to other tubulin-binding chemotherapeutic drugs, paclitaxel promotes the assembly of tubulin into microtubules and prevents the dissociation of microtubules, blocking cell cycle progression, preventing mitosis, and inhibiting tumour growth. Orth et al. found that paclitaxel leads to radiosensitisation via overexpression of mitotic Aurora kinase A (AURKA) and its cofactor Targeting protein for xenopus kinesin-like protein2 (TPX2) [56]. As a result, paclitaxel can increase the rate of apoptosis in tumour cells, release tumour antigens, and may enhance the phagocytosis of antigen-presenting cells. Furthermore, paclitaxel decreases the number and activity of Tregs, increase pro-inflammatory cytokines such as IL-10 and stimulates dendritic cell-mediated antigen presentation [57].

Indeed, growing evidence suggests the immunomodulatory properties of radiotherapy and conventional chemotherapy [23, 40, 58, 59]. Mechanistic evidence such as the induction of ICD by both treatment modalities, the alteration of tumour immunogenicity and the release of pro-inflammatory cytokines by both treatment modalities supports the preclinical rationale that the combination of radiotherapy and chemotherapy enhances immune-mediated antitumor effects (see Fig. 2).
Several immune checkpoint inhibitors have been investigated as monotherapy as well as in combined treatment approaches [58, 60, 61]. At present, the most promising drugs target the cytotoxic T-lymphocyteassociated antigen 4 (CTLA-4) e.g. ipilimumab, tremelimumab and programmed cell death protein 1 (PD-1) e.g. nivolumab, pembrolizumab, sintilimab and its ligand (PD-L1) e.g. atezolizumab and durvalumab. Benefits observed with immunotherapy alone are unfortunately limited to a small population of patients for whom a combination radio- and chemotherapy together with immunotherapy could be beneficial [12, 46, 58, 61-63].

CTLA-4 inhibition has shown considerable antitumor efficacy in melanoma and is still under investigation in NSCLC [58]. CTLA-4 is a member of an immunoglobulin-related receptors family which is expressed by activated $\mathrm{T}$ cells and transmits an inhibitory signal to $\mathrm{T}$ cells [64]. The complete mechanism of the CTLA-4 pathway remains unclear. However, latest evidence suggests that CTLA-4 recruits a phosphatase to the $\mathrm{T}$ cell receptor (TCR) and attenuates the signal [65]. The idea to combine radiotherapy with anti-CTLA-4 antibody (ipilimumab) was supported by a clinical case of a complete and durable abscopal response in metastatic NSCLC [66]. In 2018, Formenti et al. showed that the combination of RT and CTLA- 4 inhibition induced systemic anti-tumour $\mathrm{T}$ cell response in 21 patients with chemo-refractory metastatic NSCLC [58]. In contrast, anti-CTLA-4 antibodies had failed to demonstrate significant efficacy alone or in combination with chemotherapy.

Based on current preclinical and clinical data, the inhibition of the PD-1/PD-L1 pathway is the most explored immunotherapy strategy in metastatic NSCLC $[8$, 60, 61, 67-69]. PD-1 regulates T-cell and can limit the activity of antigen-specific $\mathrm{T}$ cells in the tumour and TME. PD-1 interacts with two ligands, PD-L1 and PDL2. If PD-L1, expressed by tumour cells, links with PD1 , expressed by tumour-infiltrating CD8+ T cells, cytotoxic $\mathrm{T}$ cell activity will be inhibited, which allows tumour cells to evade immune attack. Immune checkpoint inhibition with anti-PD-1 and anti-PD-L1 antibodies blocks the interaction between PD-L1 and PD-1, leading to enhanced antitumor $\mathrm{CD} 8+\mathrm{T}$ cell responses. The expression of PD-L1 on tumour cells has been reported to be positively correlated with the efficacy of anti-PD-1/PD-L1 therapy [70]. However, PD-L1-negative tumours were found to respond to PD-L1 inhibition as well $[14,61]$, questioning the role of PD-L1 expression on tumour cells as a prognostic biomarker alone. The role of host immune cells and PD-L1 expression remains unknown and the demand for more robust biological and imaging predictive biomarkers is high. Interestingly, Reynders et al. found a lower PD-L1 gene expression in 
tumour samples compared to surrounding nonmalignant lung tissue via RNA-sequencing [71]. PD-1 and PD-L1 expression could also be found in peripheral blood mononuclear cells [72, 73]. Importantly, PD-L1 expression of the tumour as well as peripheral blood compounds could vary significantly during and dramatically change after treatment $[34,74-78]$. Therefore, we see the need to monitor immune response of immunotherapy and combination treatments. Correlative studies of ICD need to be considered in order to predict tumour response as well as durable tumour control (see Table 1). Fujimoto et al. found that alteration of tumour cell PD-L1 expression after concurrent CRT in locally-advanced NSCLC was significantly associated with patient prognosis [34]. Wang et al. measured PDL1 expression in circulating tumour cells (CTCs) before radio- or chemoradiotherapy in NSCLC and found PDL1 positive patients ( $\geq 5 \%$ of CTCs positive for PD-L1) associated with shorter PFS [79] Patients with an increased PD-L1 expression on tumour cells after CRT had significantly worse overall survival [80]. Dovedi et al. also demonstrated that fractionated RT can lead to increased PD-L1 expression on tumour cells and limit anti-tumor immune response in murine models [32]. As a result, a combination of RT with PD-1/PD-L1 inhibition could be favourable due to restoration of systemic immunity and potentially increased efficacy of immune checkpoint inhibition depending on PD-L1 expression. Combinations of RT and PD-L1 inhibition have been investigated in vivo in several cancer types and resulted in a significantly delayed tumour growth $[32,69]$.

The Combination of radiotherapy and immunotherapy such as PD-1/PD-L1 inhibition as well as the combination of chemotherapy and immunotherapy have been investigated with synergistic antitumor effects $[23,46,49,58,59,63,66,76,81-84]$ (see Fig. 2 ). Based on the previously described mechanisms of ICD, the combination of all three treatment modalities is supported by the mechanistic evidence. However, preclinical studies administering radiotherapy, chemotherapy and immunotherapy are limited. Recently, Luo et al. reported in three different twotumour mouse models that concurrent triple therapy with RT, anti-PD-1 and cisplatin resulted in significant enhancement of the abscopal effect via the CXCR3/CXCL10 axis as well as cisplatin-induced CD8+ T cells and cytoreductive effect [63].

In summary, mechanistic evidence clearly suggests a combination of RT with PD-1/PD-L1 inhibition and chemotherapy as a very promising strategy in lung cancer. The synergistic effects of combining radio- and chemotherapy with immunotherapy need to be further investigated. Correlative studies on immune response monitoring need to be implemented.
Clinical studies reporting on combining immune checkpoint inhibition with chemoradiotherapy

Several clinical trials are available assessing the combination of PD-1/PD-L1 checkpoint inhibitors with chemoradiotherapy in NSCLC either in the concurrent or sequential setting. www.clinicaltrials.gov was last queried on $01 / 05 / 2020$ for all trials containing the words "NSCLC OR Non-Small Cell Lung Cancer" in the condition section and "chemoradiotherapy OR radiotherapy OR radiation" in the other terms section.

One thousand one hundred sixty-one trials were identified. After filtering for interventional (clinical trial) studies, 1041 trials remained. Further stratification for trials starting from 01/01/2010 and active as of 01/05/ 2020 i.e. recruiting OR active, not recruiting OR completed, 382 trials were identified. Twenty studies were selected manually based on relevance (Table 2; note the two parts of the DETERRED study). In addition, PubMed database, Google Scholar and generic internet search was performed for the above-mentioned studies to access abstracts/full publications when available.

\section{Studies on chemoradiotherapy and sequential immune check-point inhibition PACIFIC trial (NCT02125461) [85]}

The PACIFIC trial randomly assigned patients after concurrent CRT 2:1 to durvalumab, an anti-PD-L1 human IgG1 monoclonal antibody $10 \mathrm{mg} / \mathrm{kg}$ IV or placebo every 2 weeks for up to 12 months. Durvalumab was administered 1 to 42 days after completion of primary multimodal treatment. The co-primary outcome measures were PFS and OS. Secondary endpoints included 12and 18-month PFS rates, overall response rate (ORR) and safety. Of 713 randomised patients, 709 received consolidation therapy (473 in the durvalumab arm and 236 in the placebo arm). On interim analysis, median PFS from randomisation was 16.8 months with durvalumab vs 5.6 months with placebo; 12 -month PFS rate was $55.9 \%$ vs $35.3 \%$, and 18 -month PFS rate was $44.2 \%$ vs $27.0 \%$. Importantly, grades 3-4 toxicity was similar in both groups: $29.9 \%$ vs $26.1 \%$. Treatment was discontinued due to adverse events (AEs) in $15.4 \%$ of patients in the durvalumab group vs $9.8 \%$ in the placebo group.

In an updated analysis published in December 2018, the 24-month OS rate was $66.3 \%$ in the durvalumab group vs $55.6 \%$ in the placebo group. The updated PFS rates were in accordance with the previously published data. A total of 30.5 and $26.1 \%$ patients in the durvalumab and placebo group had grade $3 / 4$ AEs; 15.4 and $9.8 \%$ of the patients, respectively, discontinued the trial regimen because of AEs.

Based on the results of the interim analysis, the FDA approved durvalumab on February 16, 2018, for the treatment of patients with stage III NSCLC whose tumours are unresectable and without disease 


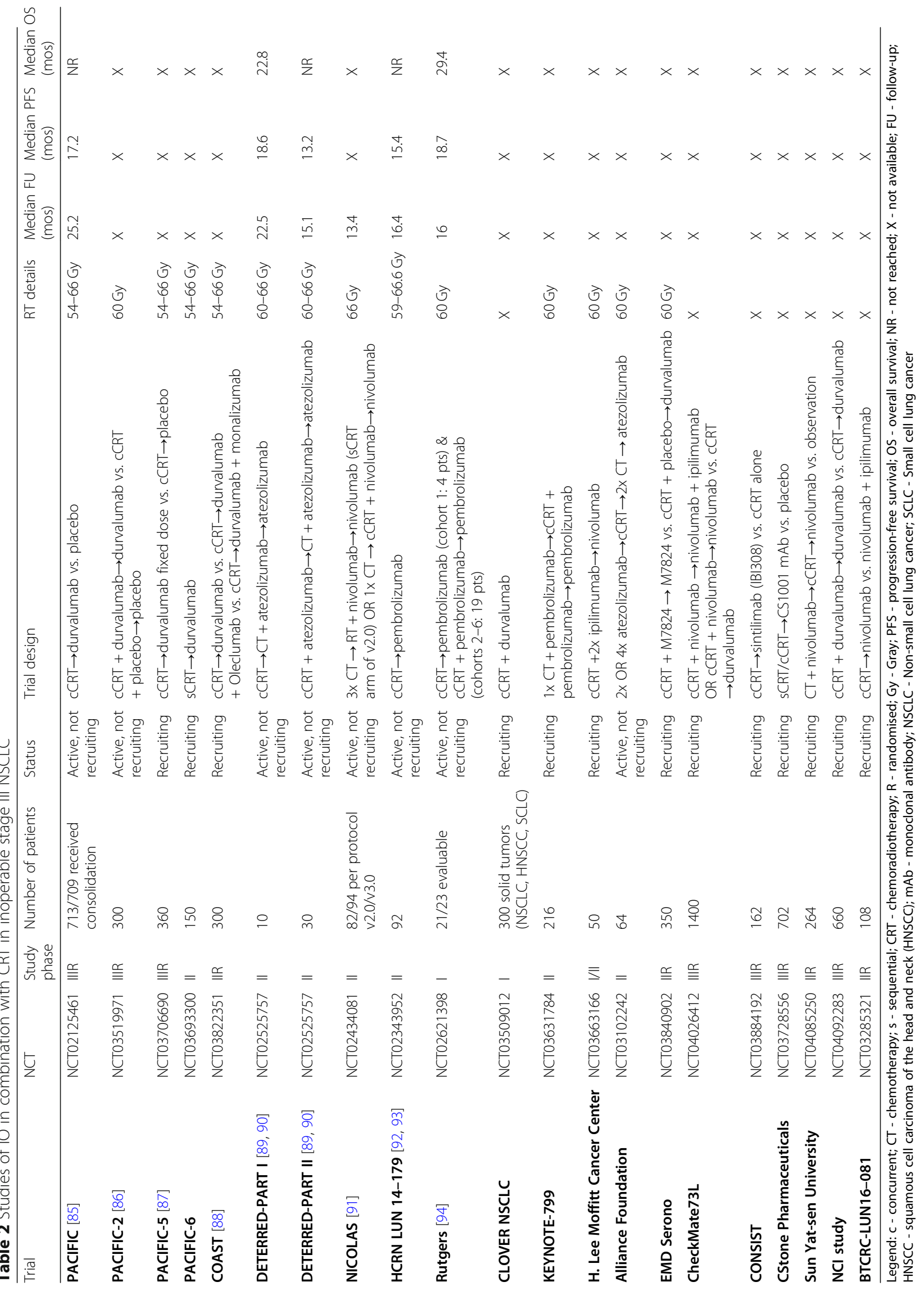


progression following CRT. The European Medicines Agency (EMA) followed suit on September 21, 2018 however choosing to approve the drug for patients with PD-L1 expressing tumours (PD-L1 at least 1\% on tumour cells assessed on archived pre-CRT tumour tissue using the VENTANA PD-L1 [SP263] immunohistochemistry assay) based on the results of an unplanned exploratory post-hoc analysis in a small patient subset, that failed to demonstrate an OS benefit in PD-L1 negative tumours. Indeed, a panel of international lung cancer experts have voiced their concern regarding this conditional approval [95].

\section{PACIFIC 5 trial (NCT03706690) [87]}

The PACIFIC 5 trial is a double-blind, placebocontrolled, multicentre study currently assessing safety and efficacy of fixed-dose durvalumab $1500 \mathrm{mg}$ IV every 4 weeks (in contrast, dosing in the PACIFIC trial was 10 $\mathrm{mg} / \mathrm{kg}$ IV every 2 weeks) in participants with unresectable stage III NSCLC who have not progressed following definitive, platinum-based concurrent CRT. EGFR or ALK genomic abberations will be capped at approximately $15 \%$. The primary endpoint is PFS. Approximately 360 patients will be randomized 2:1 to receive durvalumab or placebo. Participants will have stable disease (SD) or better following primary multimodal treatment. The study completion date is set for $01 / 2025$.

\section{PACIFIC 6 trial (NCT03693300)}

The PACIFIC 6 trial is an open-label, multicentre phase II trial currently assessing safety of fixed-dose durvalumab $1500 \mathrm{mg}$ IV every 4 weeks in participants with unresectable stage III NSCLC who have not progressed following definitive, platinum-based sequential CRT (in contrast PACIFIC 5 will assess concurrent CRT). Approximately, 150 patients will be treated with the durvalumab in Europe and North America. Radiation therapy must be completed within 28 days prior to first durvalumab administration. Participants will be treated with durvalumab in two cohorts: approximately 120 participants in the Eastern Cooperative Oncology Group Performance Status (ECOG PS) 0 to 1 cohort and approximately 30 participants in the ECOG PS 2 cohort. The primary outcome measure is the number of participants with Grade 3 and Grade 4 treatment-related AEs. Secondary endpoints include PFS, OS. The estimated study completion date is $02 / 2023$.

\section{Hoosier Cancer Research Network (HCRN) LUN 14-179 trial (NCT02343952) [92, 93]}

The LUN 14-179 is an open-label, multi-institutional phase II trial of consolidation pembrolizumab following cCRT in patients with unresectable stage III NSCLC. Following platinum-based CRT to a dose of 59-66.6 Gy, patients without disease progression after 4-8 weeks received pembrolizumab $200 \mathrm{mg}$ IV every 3 weeks for up to 1 year. The primary endpoint was median time to metastatic disease or death (TMDD). Secondary endpoints included PFS, OS, and toxicity. Ninety-three patients were enrolled and thus eligible for efficacy analysis. After a median follow-up of 16.4 months, median TMDD was not reached but the estimates of 1-yr and 2-yr OS were 80.5 and $68.7 \%$ respectively; median PFS was 15.4 months. 12-, 18-, and 24-month PFS were 59.9, 49.5, and $45.4 \%$ respectively. Five (5.4\%) had grade $3-4$ pneumonitis. There was one pneumonitis-related death. Other than dyspnoea (5.4\%), no other grade 3/4 toxicities exceeded 5\%. Median number of cycles of pembrolizumab was 13.5 (1-19). Sixteen percent received $<4$ cycles; $84 \%$ received $\geq 4$ cycles; $37 \%$ completed one-year pembrolizumab.

In a subset analysis by Anouti et al., the authors conducted a univariate analysis to evaluate which variables $(p<0.1)$ might be associated with TMDD, PFS and OS and found stage IIIA and $\geq 4$ cycles of pembrolizumab; stage IIIA, $\geq 4$ cycles of pembrolizumab, and V $20<20 \%$; stage IIIA and $\geq 4$ cycles of pembrolizumab might be associated with improved outcomes for TMDD, PFS, and OS, respectively.

\section{DETERRED trial - part I (NCT02525757) [89, 90]}

The DETERRED trial is a single institution phase II trial assessing the safety and feasibility of concurrent CRT followed by consolidation full dose carboplatin/paclitaxel (CP) with atezolizumab and maintenance atezolizumab up to 1 year for locally advanced NSCLC. The study consists of 2 parts: part I assessed sequential while part II assessed simultaneous PD-L1 blockade (see simultaneous ICI section of this review). In part I, sequential atezolizumab and $\mathrm{CP}$ after completing primary multimodal treatment was assessed in 10 patients. Any grade $\geq 3$ AEs was seen in 6/ 10 patients $(60 \%)$, with most common being pneumonia $(2 / 10 ; 20 \%)$. Three grade $\geq 3$ AEs $(30 \%)$ were attributed to atezolizumab, including dyspnoea, arthralgia and a grade 5 tracheo-oesophageal fistula. Grade 2 radiation pneumonitis (RP) was seen in 3 patients. Four patients had disease progression during atezolizumab maintenance and had died between 0.93 to 1.86 years. Based on the latest abstract, 4 patients completed atezolizumab and were in follow-up without recurrence.

\section{Coast (NCT03822351) [88]}

COAST is a phase II, open-label, multi-center, randomised multidrug platform study assessing the efficacy and safety of durvalumab alone vs. durvalumab in combination with novel agents oleclumab or monalizumab in locally advanced, unresectable, stage III NSCLC. Approximately 300 patients will be randomized 1:1:1. Participants will have stable disease (SD) or better following primary cCRT. Estimated completion date is planned in 2023. 


\section{Alliance foundation study (NCT03102242)}

Single arm open-label multicentre non-randomised phase II trial assessing induction immunotherapy with atezolizumab. The study is currently active but not recruiting with an estimated enrolment of 64 subjects. Participants received either 2 or 4 cycles of induction atezolizumab 1200 mg IV every 3 weeks with restaging performed after cycle 2 and cycle 4 . In case of progressive disease after cycle 2 and still stage III and eligible for curative-intent therapy, patients were referred for taxane-platinum combination CRT to a dose of 60 Gy otherwise after the 4 planned cycles. After cCRT, 2 cycles of consolidation chemotherapy with carboplatin AUC6 and paclitaxel $200 \mathrm{mg} / \mathrm{m}^{2}$ IV every 3 weeks beginning 3-5 weeks after completion of radiation was delivered followed by adjuvant atezolizumab $1200 \mathrm{mg}$ IV every 3 weeks to complete 1 year of therapy from the start of induction. Importantly, anti-PDL1 therapy was interrupted during CRT. The primary endpoint is disease control rate after 12 weeks induction.

\section{CONSIST study (NCT03884192)}

The CONSIST study evaluates the safety/efficacy of consolidation therapy with sintilimab (IBI308), an anti-PD1 recombinant human monoclonal antibody after cCRT for unresectable, locally advanced stage III NSCLC. In this open-label, multicentre, randomised phase III study, patients receive cCRT followed by observation vs. consolidation sintilimab $200 \mathrm{mg}$ IV every 3 weeks for a maximum of 12 months. The primary endpoint is PFS. Secondary endpoints include OS, ORR, AEs. Approximately 162 patients will be enrolled with an estimated study completion date set for $12 / 2021$.

\section{CStone pharmaceuticals (NCT03728556)}

This study evaluates the safety and efficacy of consolidation therapy with CS1001, an anti-PD-L1 fully human monoclonal antibody after cCRT for unresectable/locally advanced stage III NSCLC. In this randomised, doubleblind, multicentre, placebo-controlled phase III study, participants receive sCRT/cCRT followed by placebo vs. CS1001 $1200 \mathrm{mg}$ IV every 3 weeks for up to 24 months. The primary outcome measure is PFS. Approximately 402 participants will be enrolled with an estimated study completion date set for $08 / 2023$.

\section{Sun Yat-sen University (NCT04085250)}

This study explores the safety and efficacy of nivolumab as consolidation therapy in patients with locally advanced, unresectable stage III NSCLC who have not progressed following neo-adjuvant chemotherapy plus nivolumab and definitive cCRT. In this randomised, open-label phase II study, participants receive 2 cycles of neo-adjuvant therapy comprising docetaxel $75 \mathrm{mg} / \mathrm{m}^{2}+$ cisplatin $75 \mathrm{mg} / \mathrm{m}^{2}+$ nivolumab $360 \mathrm{mg}$ IV, once every 3 weeks followed by
cCRT with docetaxel $25 \mathrm{mg} / \mathrm{m}^{2}+$ cisplatin $25 \mathrm{mg} / \mathrm{m}^{2} \mathrm{IV}$, once a week for a total of 4 weeks and consolidation nivolumab $480 \mathrm{mg}$ IV every 4 weeks for a maximum duration of 12 months OR observation. The primary outcome measure is PFS. Secondary outcome measures are OS, ORR, AEs, symptoms and health-related quality of life. Approximately 264 participants will be enrolled with an estimated study completion date set for $11 / 2023$.

\section{Big Ten Cancer Research Consortium (BTCRC)-LUN16-081 (NCT03285321)}

This open-label, multi-centre, randomized phase II investigates consolidation immunotherapy with either nivolumab alone or the combination of nivolumab and ipilimumab following cCRT in inoperable stage III NSCLC. Participants will be randomized to either nivolumab $480 \mathrm{mg}$ IV every 4 weeks for up to 6 cycles or nivolumab $3 \mathrm{mg} / \mathrm{kg}$ IV every 2 weeks plus ipilimumab $1 \mathrm{mg} / \mathrm{kg}$ IV every 6 weeks for up to 4 cycles (in total 12 cycles of nivolumab and 4 cycles of ipilimumab). The primary endpoint is PFS. The secondary endpoints are OS, time to metastatic disease and AEs. An accrual of 108 patients is planned with an estimated study completion date set for 09/2022.

\section{Studies on chemoradiotherapy and simultaneous immune check-point inhibition Rutgers (NCT02621398) [94]}

This multicentre, non-randomised phase I trial using a 3 plus 3 design assessed the safety of timing and dosing of pembrolizumab sequentially and concurrently with taxane-platinum combination definitive photon/protonbased CRT to a dose of $60 \mathrm{~Gy}$. Dose cohorts consisted of full-dose pembrolizumab (200 mg IV every 3 weeks) 2 to 6 weeks after CRT (cohort 1: 4 patients); reduced-dose pembrolizumab (100 mg IV every 3 weeks) starting d29 of CRT (cohort 2: 4 patients); full-dose pembrolizumab starting d29 of CRT (cohort 3: 3 patients); reduced-dose pembrolizumab starting $\mathrm{d} 1$ of CRT (cohort 4: 3 patients); full-dose pembrolizumab starting d1 of CRT (cohort 5: 3 patients); and a safety expansion cohort of cohort 5 (cohort 6: 6 patients). Pembrolizumab was then continued every 3 weeks for a year. From 2016 to 2018, 23 patients were enrolled, of whom 21 received at least 1 dose of pembrolizumab and were thus evaluable. The primary endpoint was safety and tolerability. Secondary endpoints included locoregional recurrence, distantmetastasis-free survival, PFS, OS, and rate of pneumonitis. With a median follow-up of 16 months, a median of 7 (range: 0-17) cycles of pembrolizumab were administered. No dose-limiting toxicity was observed, however, 1 G5 pneumonitis occurred in the safety expansion cohort. Grade $\geq 3$ immune-related adverse events occurred in 4 patients (18\%). Median PFS was 18.7 months, and 6and 12-month PFS were 81 and 69.7\%, respectively. 


\section{PACIFIC 2 trial (NCT03519971) [86]}

The PACIFIC 2 study is a double-blind, multicentre, international randomised study assessing whether durvalumab administered simultaneous to cCRT provides additional benefit, in terms of PFS and ORR vs. cCRT alone. Approximately 300 patients with unresectable stage III NSCLC will be randomised 2:1 analogue PACIFIC to receive either fixed dose durvalumab (1500 mg) every 4 weeks and cCRT vs. placebo and cCRT. Primary endpoints are PFS and ORR (as per RECIST v1.1) assessed via blinded independent central review. Secondary endpoints include OS; OS at month 24; complete response $(\mathrm{CR})$ rate; duration of response; disease control rate; TMDD; time from randomisation to second progression; safety; and symptoms, functioning and global health status. Patients with at least SD will continue to receive durvalumab or placebo until disease progression, or until another discontinuation criterion is met. Study enrolment began in March 2018 and recruitment is ongoing.

\section{NICOLAS trial (NCT02434081) [91]}

NICOLAS is an open-label, multicentre phase II trial conducted by the European Thoracic Oncology Platform (ETOP) evaluating the safety of platinum-based CRT to a dose of 66 Gy (33 fractions in concurrent and 24 fractions in sequential arm) with concurrent nivolumab in inoperable stage III NSCLC. The protocol initially allowed CCRT or sCRT followed by nivolumab consolidation. Following PACIFIC, demonstrating safety and feasibility of sequential ICI, the trial protocol was amended to address the question of concurrent ICI (v2.0 and v3.0). However, protocol v3.0 only allowed for cCRT. Nivolumab was administered at $360 \mathrm{mg}$ IV every 3 weeks for the first 4 doses ( 8 doses in sCRT arm of v2.0), followed by $480 \mathrm{mg}$ IV every 4 weeks for up to 1 year.

The primary endpoint was safety defined by 6-month post-radiotherapy pneumonitis rate of grade $\geq 3$. A formal interim safety analysis was scheduled when the first 21 patients enrolled reached 3-months follow-up postradiotherapy. From 08/16 to 08/18, 82 patients per protocol v2.0 and v3.0 were recruited with follow-up up to 13/ $12 / 18$. Two patients died prior to treatment; thus $80 / 82$ patients were evaluable. For the first 21 patients, no grade $\geq 3$ pneumonitis was observed by the end of the 3 month post-radiotherapy follow-up period confirming safety. With a median follow-up of 13.4 months, among the 80 evaluable patients, 8 grade 3 pneumonitis events were observed, with no higher-grade event. Fatal events were observed in 7 patients, of which 1 (autoimmune disorder) was potentially associated with nivolumab. Furthermore, 1-year PFS is planned in the expanded patient cohort of all enrolled patients and is eagerly awaited.

\section{DETERRED trial - part II (NCT02525757) [89, 90]}

The DETERRED - part II trial is a single institution phase II trial assessing the safety and feasibility of simultaneous PD-L1 blockade with atezolizumab and concurrent CRT followed by consolidation full dose carboplatin/paclitaxel (CP) with atezolizumab and maintenance atezolizumab up to 1 year for locally advanced NSCLC. Thirty patients with inoperable stage III NSCLC were included. Atezolizumab was administered at 1200 mg IV every 3 weeks for up to 1 year from the first dose. Radiation dose at 60-66 Gy in 30-33 fractions was combined with weekly low dose CP, followed by 2 cycles of full dose CP. Severe AEs grade $\geq 3$ were defined within 15 weeks of start of primary multimodal treatment or any immune-related AEs during ICB treatment. Evaluable patients had at least one dose of atezolizumab. 17/ 30 patients had any grade $\geq 3$ AEs (57\%), with pneumonia being the most common $(6 / 30 ; 20 \%)$. Three $(10 \%)$ were attributed to atezolizumab (dyspnoea, fatigue and heart failure). Radiation pneumonitis was observed in 3 patients, with 2 grade 2 and 1 grade 3, hence atezolizumab was discontinued. Four patients had progressed and 4 had died, 2 due to disease and 2 due to treatment (neutropenic sepsis and gastric haemorrhage). All other patients had completed primary treatment and were on maintenance atezolizumab (5-19 doses). Updated efficacy results are pending however, this result suggests feasibility of concurrent atezolizumab administration with concurrent CRT followed by maintenance treatment with atezolizumab.

\section{Clover (NCT03509012)}

The CLOVER trial is an open-label, multicentre phase I trial currently assessing safety and tolerability of durvalumab +/tremelimumab in combination with cCRT in patients with squamous cell carcinoma of the head and neck (HNSCC), NSCLC and SCLC. In the NSCLC arms, patients with unresectable stage III NSCLC receive a platinum doublet with durvalumab concurrently. Approximately 360 participants are planned and will be enrolled in North America, Europe and Asia. Primary endpoints are number of subjects with dose limiting toxicities (DLTs) and adverse events.

\section{KEYNOTE-799 (NCT03631784)}

The KEYNOTE-799 trial is an open-label multicentre nonrandomised phase II trial of pembrolizumab in combination with a platinum doublet chemotherapy regimen. Patients will receive 1 cycle of pembrolizumab $200 \mathrm{mg}$ IV on d1 with carboplatin/paclitaxel or cisplatin/pemetrexed and approximately 3 weeks later cCRT with the same regimens to a dose of 60 Gy with $2 x$ concurrent pembrolizumab followed by 14 additional cycles pembrolizumab consolidation every 3 weeks. The primary endpoints are $\geq 3$ pneumonitis rates and remission status. Secondary endpoints include PFS, OS, AEs. The estimated enrolment of 216 patients is planned. 


\section{H. Lee Moffitt Cancer Center and Research Institute study (NCT03663166)}

Open-label multicentre non-randomised phase I/II trial assessing platinum-based cCRT to a dose of $60 \mathrm{~Gy}$ with concurrent ipilimumab $1 \mathrm{mg} / \mathrm{kg}$ IV on $\mathrm{d} 1$ and $\mathrm{d} 22$ followed by nivolumab $480 \mathrm{mg}$ IV monotherapy every 4 weeks for up to 1 year. Primary endpoints are unacceptable toxicity status at the end of an 8-week safety observation period and 12month PFS. An estimated enrolment of 50 participants is planned and an estimated study completion date in 2027.

\section{EMD Serono study (NCT03840902)}

A multicentre, double-blind randomised controlled study assessing safety and efficacy of platinum-based cCRT with M7824, a novel bifunctional anti-PDL1/TGF $\beta$ trap fusion protein followed by M7824. Patients will be randomised to either standard of care platinum-based cCRT to a dose of $60 \mathrm{~Gy}+$ placebo followed by durvalumab consolidation or cCRT + M7824 followed by M7824. The primary endpoint is PFS and secondary endpoints including AEs, OS analysis. Enrolment of 350 patients is planned with an estimated completion date set for 2028.

\section{CheckMate73L (NCT04026412)}

The CheckMate73L is an open-label, multicentre, randomised phase III trial comparing cCRT plus nivolumab followed by nivolumab plus ipilimumab OR cCRT plus nivolumab followed by nivolumab vs. standard of care platinum-based cCRT followed by durvalumab. The coprimary endpoints are PFS and OS. An estimated enrolment of 1400 participants is planned and estimated study completion set for end of 2024.

\section{NCl study (NCT04092283)}

This study explores the efficacy of cCRT plus durvalumab as concomitant and consolidation therapy or consolidation therapy alone (SoC) in patients with locally advanced, unresectable stage III NSCLC. In this randomised, open--label phase III study, in the concurrent arm participants receive platinum-based cCRT plus durvalumab on $\mathrm{d} 1 \& \mathrm{~d} 15$ of cycle 1 and $\mathrm{d} 1$ of cycle 2 followed by durvalumab every 4 weeks starting within 14 days after the last dose of radiation for 12 cycles. In contrast, in the standard arm, participants receive standard platinum-based cCRT followed by durvalumab also every 4 weeks for a year. The primary endpoint is OS. Secondary endpoints include LRC, PFS, ORR and AEs. Approximately 660 participants will be enrolled with an estimated study completion date set for $10 / 2028$.

\section{Conclusion}

Based on current clinical data, concurrent CRT with maintenance PD-1/PD-L1 inhibition in inoperable stage III
NSCLC is a safe and effective multimodal approach with unprecedented median PFS ranging from 16 to 20 months und 2-year OS rates of 60 to $70 \%$. It represents a complex tri-modal approach with high efficacy regarding local and distant tumour control and moderate therapy-related side effects. Hitherto, there is a void with respect to robust predictive biomarkers. Going forward, identification of predictive biological biomarkers for this intensified treatment will be challenging. To optimise development of biomarkers several aspects must be taken in consideration:

A. Reported biomarkers (PD-L1 expression, TMB, IFN gamma gene signature) for immune check-point inhibition as a monotherapy should be tested in the combined multimodal setting.

B. These biomarkers need to be evaluated for correlation with principal patient- and treatmentrelated factors like gender, age, ECOG, smoking status, tumour volume, histology and type of tumour response (necrotic vs other).

C. It is important to perform a longitudinal analysis of potential biomarkers across all modalities of combined therapy to analyse dynamic and temporary changes before and during every treatment phase.

D. Immunogenic cell death potential of conventional chemotherapeutics (platinum, paclitaxel, pemetrexed etc.), different radiation treatment modes (ultrahypovs hypo- vs conventional fractionation) and their combinations need to be determined.

E. It will be necessary to characterise the host immune system in order to evaluate changes during multimodal treatment.

F. Presumably, complexity and plasticity of immune reactions will lead to establishment of a marker panel in order to achieve an effective multimodal treatment personalisation.

Additionally, there has been growing interest in imaging biomarkers particularly with the use of noninvasive molecular imaging agents that can assess expression of immune targets.

In summary, there are a plethora of studies currently assessing CRT plus IO combinations. Incorporation of ICIs with accelerated hypofractionated radiotherapy in treatment concepts could warrant further exploration to cater for patients who present with reduced performance status. Certainly, the question of additional benefit of simultaneous and consolidation ICI with concurrent CRT will be answered in the coming years. However, the duration of ICI consolidation needs to be further explored taking into account cost effectiveness and health economic issues. Finally, it is safe to say that IO is a cornerstone of treatment for inoperable stage III NSCLC and going forward, refinement of this tri-modal concept will only serve to ameliorate patient outcome. 


\section{Abbreviations}

AEs: Adverse events; ATP: Adenosine-5'-triphosphate; AURKA: Aurora kinase A; Cl: Confidence interval; CP: Carboplatin/paclitaxel;

CRT: Chemoradiotherapy; CTC: Circulating tumour cell; CTLA-4: Cytotoxic Tlymphocyte-associated antigen 4; DAMP: Danger-associated molecular pattern; DC: Dendritic cell; DNA: Deoxyribonucleic acid; ECOG PS: Eastern Cooperative Oncology Group Performance Status; EMA: European Medicines Agency; ETOP: European Thoracic Oncology Platform; FDA: Food and Drug Administration; HMGB1: High mobility group box 1; HR: Hazard ratio; ICB: Immune checkpoint blockade; ICD: Immunogenic cell death; ICl: Immune-checkpoint inhibitor; IFN: Interferon; IgG: Immunoglobulin G; IL: Interleukin; MHC: Major histocompatibility complex; mOS: Median overall survival; NK: Natural killer; NKG2D: Natural killer group 2 member D; NKT: Natural killer T; NSCLC: Non-small cell lung cancer; ORR: Overall response rate; OS: Overall survival; PD: Progressive disease; PD-

1: Programmed cell death protein 1; PD-L1: Programmed cell death ligand 1; PFS: Progression-free survival; pre-cCRT: Pre-concurrent chemoradiotherapy; RECIST: Response Evaluation Criteria In Solid Tumours; RNA: Ribonucleic acid; RP: Radiation pneumonitis; RT: Radiotherapy; RTOG: Radiation Therapy Oncology Group; SD: Stable disease; TCR: T cell receptor; TGF $\beta$ : Transforming growth factor- $\beta$; TMB: Tumour mutational burden; TME: Tumour microenvironment; TMDD: Time to metastatic disease or death; TNF: Tumour necrosis factor; TPX2: Targeting protein for xenopus kinesin-like protein 2; v: Version; yr: Year

\section{Acknowledgements}

The piece has not been previously published and is not under consideration elsewhere. The persons listed as authors have given their approval for the submission.

\section{Conflict of interest}

On behalf of all Authors, the corresponding Author states that there is no conflict of interest related to this study.

\section{Authors' contributions}

All authors reviewed, analysed and interpreted the data. All authors helped in drafting the manuscript. All authors read and gave their stamp of approval for the submission of the final version of the manuscript.

\section{Funding}

None.

\section{Availability of data and materials}

The datasets used and analysed during the current study are available from the corresponding author on reasonable request.

\section{Ethics approval and consent to participate}

Not applicable.

\section{Consent for publication}

Not applicable.

\section{Competing interests}

The authors declare that they have no competing interests.

\section{Author details}

'Department of Radiation Oncology, University Hospital, LMU Munich, Marchioninistrasse 15, 81377 Munich, Germany. ${ }^{2}$ Comprehensive Pneumology Center Munich (CPC-M), Member of the German Center for Lung Research (DZL), Munich, Germany. ${ }^{3}$ German Cancer Consortium (DKTK), Partner Site Munich, Munich, Germany. ${ }^{4}$ Department of Internal Medicine V, Ludwig-Maximilians-University, Munich, Germany.

Received: 16 January 2020 Accepted: 9 June 2020

Published online: 09 July 2020

\section{References}

1. Postmus P, Kerr K, Oudkerk M, Senan S, Waller D, Vansteenkiste J, et al. Early and locally advanced non-small-cell lung cancer (NSCLC): ESMO clinical practice guidelines for diagnosis, treatment and follow-up. Ann Oncol. 2017; 28:iv1-iv21.
2. Choi HS, Jeong BK, Jeong H, Lee YH, Ha IB, Song JH, et al. Application of the new 8th TNM staging system for non-small cell lung cancer: treated with curative concurrent chemoradiotherapy. Radiat Oncol. 2017;12:122.

3. Ettinger DS, Aisner DL, Wood DE, Akerley W, Bauman J, Chang JY, et al. NCCN guidelines insights: non-small cell lung cancer, version 5.2018. J Natl Compr Cancer Netw. 2018;16:807-21.

4. Käsmann L, Niyazi M, Blanck O, Baues C, Baumann R, Dobiasch S, et al. Predictive and prognostic value of tumor volume and its changes during radical radiotherapy of stage III non-small cell lung cancer. Strahlenther Onkol. 2018;194:79-90.

5. Taugner J, Käsmann L, Eze C, Dantes M, Roengvoraphoj O, Gennen K, et al. Survival score to characterize prognosis in inoperable stage III NSCLC after chemoradiotherapy. Transl Lung Cancer Res. 2019;8:593.

6. Abdel-Rahman O. Outcomes of surgery as part of the Management of Metastatic non-small-cell lung cancer: a surveillance, epidemiology and end results database analysis. Cancer Investig. 2018;36:238-45.

7. Walraven I, Damhuis R, Ten Berge M, Rosskamp M, van Eycken L, de Ruysscher D, et al. Treatment variation of sequential versus concurrent Chemoradiotherapy in stage III non-small cell lung cancer patients in the Netherlands and Belgium. Clin Oncol. 2017;29:e177-85.

8. Antonia SJ, Villegas A, Daniel D, Vicente D, Murakami S, Hui R, et al. Overall survival with durvalumab after chemoradiotherapy in stage III NSCLC. N Engl J Med. 2018;379:2342-50.

9. Käsmann L, Eze C, Dantes M, Roengvoraphoj O, Niyazi M, Belka C, et al. State of clinical research of radiotherapy/chemoradiotherapy and immune checkpoint inhibitor therapy combinations in solid tumours-a German radiation oncology survey. Eur J Cancer. 2019;108:50-4.

10. Käsmann L, Taugner J, Manapov F. Chemo-/immuno-/radiotherapy combination in treatment of solid cancer. Oncotarget. 2019;10:5387.

11. O'Rourke N, iFiguls MR, Bernadó NF, Macbeth F. Concurrent chemoradiotherapy in non-small cell lung cancer. Cochrane Database Syst Rev. 2010;6:1465-858.

12. Borghaei $H$, Paz-Ares $L$, Horn L, Spigel DR, Steins M, Ready NE, et al. Nivolumab versus docetaxel in advanced nonsquamous non-small-cell lung cancer. N Engl J Med. 2015;373:1627-39.

13. Brahmer J, Reckamp KL, Baas P, Crinò L, Eberhardt WE, Poddubskaya E, et al. Nivolumab versus docetaxel in advanced squamous-cell non-small-cell lung cancer. N Engl J Med. 2015;373:123-35.

14. Gandhi L, Rodríguez-Abreu D, Gadgeel S, Esteban E, Felip E, De Angelis F, et al. Pembrolizumab plus chemotherapy in metastatic non-small-cell lung cancer. N Engl J Med. 2018;378:2078-92.

15. Paz-Ares L, Luft A, Vicente $D$, Tafreshi $A$, Gümüş $M$, Mazières J, et al. Pembrolizumab plus chemotherapy for squamous non-small-cell lung cancer. N Engl J Med. 2018;379:2040-51.

16. Foster CC, Sher DJ, Rusthoven CG, Verma V, Spiotto MT, Weichselbaum RR, et al. Overall survival according to immunotherapy and radiation treatment for metastatic non-small-cell lung cancer: a National Cancer Database analysis. Radiat Oncol. 2019;14:18. https://doi.org/10.1186/s13014-019-1222-3.

17. Lauber K, Ernst A, Orth M, Herrmann M, Belka C. Dying cell clearance and its impact on the outcome of tumor radiotherapy. Front Oncol. 2012;2:116.

18. Olive PL. The role of DNA single-and double-strand breaks in cell killing by ionizing radiation. Radiat Res. 1998;150:542-51.

19. Frey B, Rückert M, Deloch $L$, Rühle PF, Derer $A$, Fietkau R, et al. Immunomodulation by ionizing radiation-impact for design of radioimmunotherapies and for treatment of inflammatory diseases. Immunol Rev. 2017;280:231-48.

20. Abuodeh Y, Venkat P, Kim S. Systematic review of case reports on the abscopal effect. Curr Probl Cancer. 2016;40:25-37.

21. Ng J, Dai T. Radiation therapy and the abscopal effect: a concept comes of age. Ann Transl Med. 2016;4:118.

22. Grass GD, Krishna N, Kim S. The immune mechanisms of abscopal effect in radiation therapy. Curr Probl Cancer. 2016;40:10-24.

23. Demaria S, Ng B, Devitt ML, Babb JS, Kawashima N, Liebes L, et al. lonizing radiation inhibition of distant untreated tumors (abscopal effect) is immune mediated. Int J Radiat Oncol Biol Phys. 2004;58:862-70.

24. Ko EC, Raben D, Formenti SC. The integration of radiotherapy with immunotherapy for the treatment of non-small cell lung cancer. Clin Cancer Res. 2018;24:5792-806.

25. Chang M-C, Chen Y-L, Lin H-W, Chiang Y-C, Chang C-F, Hsieh S-F, et al. Irradiation enhances abscopal anti-tumor effects of antigen-specific immunotherapy through regulating tumor microenvironment. Mol Ther. 2018;26:404-19. 
26. Gupta A, Probst HC, Vuong V, Landshammer A, Muth S, Yagita H, et al. Radiotherapy promotes tumor-specific effector CD8+ T cells via dendritic cell activation. J Immunol. 2012;189:558-66.

27. Qinfeng S, Depu W, Xiaofeng Y, Shah W, Hongwei C, Yili W. In situ observation of the effects of local irradiation on cytotoxic and regulatory $T$ lymphocytes in cervical cancer tissue. Radiat Res. 2013;179:584-9.

28. Son C-H, Bae J-H, Shin D-Y, Lee H-R, Jo W-S, Yang K, et al. Combination effect of regulatory $T$-cell depletion and ionizing radiation in mouse models of lung and colon cancer. Int J Radiat Oncol Biol Phys. 2015;92:390-8.

29. Reits EA, Hodge JW, Herberts CA, Groothuis TA, Chakraborty M, Wansley EK, et al. Radiation modulates the peptide repertoire, enhances MHC class I expression, and induces successful antitumor immunotherapy. J Exp Med. 2006:203:1259-71.

30. Sridharan $V$, Schoenfeld JD. Immune effects of targeted radiation therapy for cancer. Discov Med. 2015;19:219-28.

31. Zeng H, Zhang W, Gong Y, Xie C. Radiotherapy activates autophagy to increase CD8+ T cell infiltration by modulating major histocompatibility complex class-I expression in non-small cell lung cancer. J Int Med Res. 2019;47:3818-30.

32. Dovedi SJ, Cheadle EJ, Popple AL, Poon E, Morrow M, Stewart R, et al. Fractionated radiation therapy stimulates antitumor immunity mediated by both resident and infiltrating polyclonal T-cell populations when combined with PD-1 blockade. Clin Cancer Res. 2017;23:5514-26.

33. Choe E-A, Cha YJ, Kim J-H, Pyo KH, Hong MH, Park SY, et al. Dynamic changes in PD-L1 expression and CD8+ T cell infiltration in non-small cell lung cancer following chemoradiation therapy. Lung Cancer. 2019;136:30-6.

34. Fujimoto D, Uehara K, Sato Y, Sakanoue I, Ito M, Teraoka S, et al. Alteration of PD-L1 expression and its prognostic impact after concurrent chemoradiation therapy in non-small cell lung cancer patients. Sci Rep. 2017;7:11373.

35. Kim J-Y, Son Y-O, Park S-W, Bae J-H, Chung JS, Kim HH, et al. Increase of NKG2D ligands and sensitivity to NK cell-mediated cytotoxicity of tumor cells by heat shock and ionizing radiation. Exp Mol Med. 2006;38:474-84

36. Gasser S, Orsulic S, Brown EJ, Raulet DH. The DNA damage pathway regulates innate immune system ligands of the NKG2D receptor. Nature. 2005;436:1186-90.

37. Burnette BC, Liang H, Lee Y, Chlewicki L, Khodarev NN, Weichselbaum RR, et al. The efficacy of radiotherapy relies upon induction of type I interferondependent innate and adaptive immunity. Cancer Res. 2011;71:2488-96.

38. Zhang J, Nakatsugawa S, Niwa O, Ju G, Liu S. lonizing radiation-induced IL-1 alpha, IL-6 and GM-CSF production by human lung cancer cells. Chin Med J. 1994;107:653-7.

39. Dong X-R, Wang J-N, Liu L, Chen X, Chen M-S, Chen J, et al. Modulation of radiation-induced tumour necrosis factor-a and transforming growth factor $\beta 1$ expression in the lung tissue by Shengqi Fuzheng injection. Mol Med Rep. 2010;3:621-7.

40. Golden EB, Frances D, Pellicciotta I, Demaria S, Helen Barcellos-Hoff M, Formenti SC. Radiation fosters dose-dependent and chemotherapy-induced immunogenic cell death. Oncoimmunology. 2014;3:e28518.

41. Käsmann L, Eze C, Manapov F. Stereotactic body radiation therapy (SBRT) combined with immune check-point inhibition $(\mathrm{ICl})$ in advanced lung cancer: which metastatic site should be irradiated to induce immunogenic cell death? Int J Radiat Oncol Biol Phys. 2020;S0360-3016(20):30987.

42. Mondini M, Nizard M, Tran T, Mauge L, Loi M, Clémenson C, et al. Synergy of radiotherapy and a cancer vaccine for the treatment of HPV-associated head and neck cancer. Mol Cancer Ther. 2015;14:1336-45.

43. Matsumura S, Wang B, Kawashima N, Braunstein S, Badura M, Cameron TO, et al. Radiation-induced CXCL16 release by breast cancer cells attracts effector T cells. J Immunol. 2008;181:3099-107.

44. Chakravarty PK, Alfieri A, Thomas EK, Beri V, Tanaka KE, Vikram B, et al. Flt3ligand administration after radiation therapy prolongs survival in a murine model of metastatic lung cancer. Cancer Res. 1999:59:6028-32.

45. Lee $Y$, Auh SL, Wang $Y$, Burnette B, Wang $Y$, Meng $Y$, et al. Therapeutic effects of ablative radiation on local tumor require CD8+ T cells: changing strategies for cancer treatment. Blood. 2009;114:589-95.

46. Zheng $\mathrm{H}$, Zeltsman $\mathrm{M}$, Zauderer MG, Eguchi T, Vaghiiani RG, Adusumilli PS Chemotherapy-induced immunomodulation in non-small-cell lung cancer: a rationale for combination chemoimmunotherapy. Immunotherapy. 2017;9:913-27.

47. Gameiro SR, Caballero JA, Hodge JW. Defining the molecular signature of chemotherapy-mediated lung tumor phenotype modulation and increased susceptibility to T-cell killing. Cancer Biother Radiopharm. 2012;27:23-35.

48. Okita R, Yukawa T, Nojima Y, Maeda A, Saisho S, Shimizu K, et al. MHC class I chain-related molecule a and $\mathrm{B}$ expression is upregulated by cisplatin and associated with good prognosis in patients with non-small cell lung cancer. Cancer Immunol Immunother. 2016;65:499-509.

49. Boeckman HJ, Trego KS, Turchi JJ. Cisplatin sensitizes cancer cells to ionizing radiation via inhibition of nonhomologous end joining. Mol Cancer Res. 2005;3:277-85.

50. Liu M, Ma S, Liu M, Hou Y, Liang B, Su X, et al. Synergistic killing of lung cancer cells by cisplatin and radiation via autophagy and apoptosis. Oncol Lett. 2014;7:1903-10.

51. Davou Gl, Chuwang NJ, Essien UC, Choji TPP, Echeonwu BC, Lugos MD. Cytotoxicity analysis of etoposide and cisplatin on cell lines from human lung cancer and normal human lung. Int Res J Med Med Sci. 2019;7(2): 40-7.

52. Johnson TS, Terrell CE, Millen SH, Katz JD, Hildeman DA, Jordan MB. Etoposide selectively ablates activated T cells to control the immunoregulatory disorder hemophagocytic lymphohistiocytosis. J Immunol. 2014;192:84-91.

53. Ferraro C, Quemeneur L, Fournel S, Prigent A, Revillard J, Bonnefoy-Berard $\mathrm{N}$. The topoisomerase inhibitors camptothecin and etoposide induce a CD95-independent apoptosis of activated peripheral lymphocytes. Cell Death Differ. 2000;7:197-206.

54. Stahnke K, Fulda S, Friesen C, Strauß G, Debatin K-M. Activation of apoptosis pathways in peripheral blood lymphocytes by in vivo chemotherapy. Blood J Am Soc Hematol. 2001;98:3066-73.

55. Schaer DA, Geeganage S, Amaladas N, Lu ZH, Rasmussen ER, Sonyi A, et al. The folate pathway inhibitor pemetrexed pleiotropically enhances effects of cancer immunotherapy. Clin Cancer Res. 2019;25:7175-88.

56. Orth M, Unger K, Schoetz U, Belka C, Lauber K. Taxane-mediated radiosensitization derives from chromosomal missegregation on tripolar mitotic spindles orchestrated by AURKA and TPX2. Oncogene. 2018;37: $52-62$.

57. Zhu L, Chen L. Progress in research on paclitaxel and tumor immunotherapy. Cell Mol Biol Lett. 2019;24:40.

58. Formenti SC, Rudqvist N-P, Golden E, Cooper B, Wennerberg E, Lhuillier C, et al. Radiotherapy induces responses of lung cancer to CTLA-4 blockade. Nat Med. 2018;24:1845.

59. Dewan MZ, Galloway AE, Kawashima N, Dewyngaert JK, Babb JS, Formenti SC, et al. Fractionated but not single-dose radiotherapy induces an immune-mediated abscopal effect when combined with anti-CTLA-4 antibody. Clin Cancer Res. 2009;15:5379-88.

60. Reck M, Rodríguez-Abreu D, Robinson AG, Hui R, Csőszi T, Fülöp A, et al. Pembrolizumab versus chemotherapy for PD-L1-positive non-small-cell lung cancer. N Engl J Med. 2016;375:1823-33.

61. Hellmann MD, Rizvi NA, Goldman JW, Gettinger SN, Borghaei H, Brahmer JR, et al. Nivolumab plus ipilimumab as first-line treatment for advanced nonsmall-cell lung cancer (CheckMate 012): results of an open-label, phase 1, multicohort study. Lancet Oncol. 2017;18:31-41.

62. Antonia SJ, Villegas A, Daniel D, Vicente D, Murakami S, Hui R, et al. Durvalumab after chemoradiotherapy in stage III non-small-cell lung cancer. N Engl J Med. 2017;377:1919-29.

63. Luo R, Firat E, Gaedicke S, Guffart E, Watanabe T, Niedermann G. Cisplatin facilitates radiation-induced abscopal effects in conjunction with PD-1 checkpoint blockade through CXCR3/CXCL10-mediated T cell recruitment. Clin Cancer Res. 2019;25(23):7243.

64. Krummel MF, Allison JP. CD28 and CTLA-4 have opposing effects on the response of T cells to stimulation. J Exp Med. 1995;182:459-65.

65. Lee K-M, Chuang E, Griffin M, Khattri R, Hong DK, Zhang W, et al. Molecular basis of T cell inactivation by CTLA-4. Science. 1998;282:2263-6.

66. Golden EB, Demaria S, Schiff PB, Chachoua A, Formenti SC. An abscopal response to radiation and ipilimumab in a patient with metastatic nonsmall cell lung cancer. Cancer Immunol Res. 2013;1:365-72.

67. Rizvi NA, Hellmann MD, Brahmer JR, Juergens RA, Borghaei H, Gettinger S, et al. Nivolumab in combination with platinum-based doublet chemotherapy for first-line treatment of advanced non-small-cell lung cancer. J Clin Oncol. 2016;34:2969.

68. Alsaab HO, Sau S, Alzhrani R, Tatiparti K, Bhise K, Kashaw SK, et al. PD-1 and PD-L1 checkpoint signaling inhibition for cancer immunotherapy: mechanism, combinations, and clinical outcome. Front Pharmacol. 2017; 8:561

69. Deng L, Liang H, Burnette B, Beckett M, Darga T, Weichselbaum RR, et al. Irradiation and anti-PD-L1 treatment synergistically promote antitumor immunity in mice. J Clin Invest. 2014;124:687-95. 
70. Zou W, Wolchok JD, Chen L. PD-L1 (B7-H1) and PD-1 pathway blockade for cancer therapy: mechanisms, response biomarkers, and combinations. Sci Transl Med. 2016;8:328rv4.

71. Reynders K, Wauters E, Moisse M, Decaluwé H, De Leyn P, Peeters S, et al. RNA-sequencing in non-small cell lung cancer shows gene downregulation of therapeutic targets in tumor tissue compared to non-malignant lung tissue. Radiat Oncol. 2018;13:131.

72. Boffa DJ, Graf RP, Salazar MC, Hoag J, Lu D, Krupa R, et al. Cellular expression of PD-L1 in the peripheral blood of lung cancer patients is associated with worse survival. Cancer Epidemiol Prev Biomark. 2017;26: $1139-45$.

73. Arrieta O, Montes-Servín E, Hernandez-Martinez J-M, Cardona AF, Casas-Ruiz E, Crispín JC, et al. Expression of PD-1/PD-L1 and PD-L2 in peripheral T-cells from non-small cell lung cancer patients. Oncotarget. 2017:8:101994.

74. Daly ME, Monjazeb AM, Kelly K. Clinical trials integrating immunotherapy and radiation for non-small-cell lung cancer. J Thorac Oncol. 2015;10:1685-93.

75. Herter-Sprie GS, Koyama S, Korideck H, Hai J, Deng J, Li YY, et al. Synergy of radiotherapy and PD-1 blockade in Kras-mutant lung cancer. JCI Insight. 2016;1(9):e87415.

76. Gong X, Li X, Jiang T, Xie H, Zhu Z, Zhou F, et al. Combined radiotherapy and anti-PD-L1 antibody synergistically enhances antitumor effect in nonsmall cell lung cancer. J Thorac Oncol. 2017;12:1085-97.

77. Dovedi $\mathrm{S}$, Illidge T. The antitumor immune response generated by fractionated radiation therapy may be limited by tumor cell adaptive resistance and can be circumvented by PD-L1 blockade. Oncoimmunology. 2015:4:e1016709.

78. Chen G, Huang AC, Zhang W, Zhang G, Wu M, Xu W, et al. Exosomal PD-L1 contributes to immunosuppression and is associated with anti-PD-1 response. Nature. 2018;560:382.

79. Wang A, Wang H, Liu Y, Zhao M, Zhang H, Lu Z, et al. The prognostic value of PD-L1 expression for non-small cell lung cancer patients: a meta-analysis. Eur J Surg Oncol EJSO. 2015;41:450-6.

80. Gennen K, Käsmann L, Taugner J, Eze C, Karin M, Roengvoraphoj O, et al. Prognostic value of PD-L1 expression on tumor cells combined with CD8+ TIL density in patients with locally advanced non-small cell lung cancer treated with concurrent chemoradiotherapy. Radiat Oncol. 2020;15:5.

81. Liu Y, Dong Y, Kong L, Shi F, Zhu H, Yu J. Abscopal effect of radiotherapy combined with immune checkpoint inhibitors. J Hematol OncolJ Hematol Oncol. 2018;11:104. https://doi.org/10.1186/s13045-018-0647-8.

82. Dovedi SJ, Adlard AL, Lipowska-Bhalla G, McKenna C, Jones S, Cheadle EJ, et al. Acquired resistance to fractionated radiotherapy can be overcome by concurrent PD-L1 blockade. Cancer Res. 2014;74:5458-68.

83. Wang W, Green M, Liu JR, Lawrence TS, Zou W. CD8+ T cells in immunotherapy, radiotherapy, and chemotherapy. In: Oncoimmunology. Cham: Springer; 2018. p. 23-39.

84. Vanpouille-Box C, Alard A, Aryankalayil MJ, Sarfraz Y, Diamond JM, Schneider RJ, et al. DNA exonuclease Trex1 regulates radiotherapy-induced tumour immunogenicity. Nat Commun. 2017;8:15618.

85. Antonia SJ, Villegas A, Daniel D, Vicente D, Murakami S, Hui R, et al. Overall survival with Durvalumab after Chemoradiotherapy in stage III NSCLC. N Engl J Med. 2018;379:2342-50. https://doi.org/10.1056/NEJMoa1809697.

86. Bradley JD, Nishio M, Okamoto I, Newton MD, Trani L, Shire NJ, et al. PACIFIC-2: phase 3 study of concurrent durvalumab and platinum-based chemoradiotherapy in patients with unresectable, stage III NSCLC. J Clin Oncol. 2019;37:-TPS8573. https://doi.org/10.1200/JCO.2019.37.15_suppl. TPS8573.

87. Wu Y, Wang L, Sendur M, Kim Y, Zhu Z, Cheng Y, et al. 339TiP PACIFIC-5: phase III study of durvalumab after either concurrent or sequential chemoradiotherapy (CRT) in patients with stage III NSCLC. Ann Oncol. 2019; 30:mdz438.

88. Herbst R, Barlesi F, Paz-Ares L, Raben D, Aggarwal C, Bothos J, et al. P1. 0428 COAST: Durvalumab alone or with novel agents for locally advanced, Unresectable, stage III non-small cell lung cancer. J Thorac Oncol. 2019;14: S450-1.

89. Lin SH, Lin Y, Price J, Parker M, Gomez DR, Welsh JW, et al. DETERRED: PD-L1 blockade to evaluate the safety of lung cancer therapy using carboplatin, paclitaxel, and radiation combined with MPDL3280A (atezolizumab). J Clin Oncol. 2017;35:3064. https://doi.org/10.1200/JCO. 2017.35.15_suppl.3064

90. Lin S, Lin X, Clay D, Yao L, Mok I, Gomez D, et al. OA01.06 DETERRED: phase II trial combining Atezolizumab concurrently with Chemoradiation therapy in locally advanced non-small cell lung cancer. J Thorac Oncol. 2018;13: S320-1. https://doi.org/10.1016/j.jtho.2018.08.237.

91. Peters S, Felip E, Dafni U, Belka C, Guckenberger M, Irigoyen A, et al. Safety evaluation of nivolumab added concurrently to radiotherapy in a standard first line chemo-radiotherapy regimen in stage III non-small cell lung cancer-the ETOP NICOLAS trial. Lung Cancer Amst Neth. 2019;133:83-7. https://doi.org/10.1016/j.lungcan.2019.05.001.

92. Durm GA, Althouse SK, Sadiq AA, Jalal SI, Jabbour S, Zon R, et al. Phase ॥ trial of concurrent chemoradiation with consolidation pembrolizumab in patients with unresectable stage III non-small cell lung cancer: Hoosier cancer research network LUN 14-179. J Clin Oncol. 2018;36:8500. https://doi. org/10.1200/JCO.2018.36.15_suppl.8500.

93. Anouti B, Althouse S, Durm G, Hanna N. Prognostic variables associated with improved outcomes in patients with stage III NSCLC treated with chemoradiation followed by consolidation Pembrolizumab: a subset analysis of a phase II study from the Hoosier cancer research network LUN 14-179. Clin Lung Cancer. 2020;21(3):288-93. https://doi.org/10.1016/j.cllc.2019.06. 009.

94. Jabbour SK, Berman AT, Decker RH, et al. Phase 1 trial of Pembrolizumab administered concurrently with Chemoradiotherapy for locally advanced non-small cell lung cancer: a nonrandomized controlled trial. JAMA Oncol. 2020;6(6):848-55. https://doi.org/10.1001/jamaoncol.2019.6731.

95. Peters $S$, Dafni $U$, Boyer $M$, et al. Position of a panel of international lung cancer experts on the approval decision for use of durvalumab in stage III non-small-cell lung cancer (NSCLC) by the Committee for Medicinal Products for human use (CHMP). Ann Oncol. 2019;30(2):161-5. https://doi. org/10.1093/annonc/mdy553.

\section{Publisher's Note}

Springer Nature remains neutral with regard to jurisdictional claims in published maps and institutional affiliations.
Ready to submit your research? Choose BMC and benefit from:

- fast, convenient online submission

- thorough peer review by experienced researchers in your field

- rapid publication on acceptance

- support for research data, including large and complex data types

- gold Open Access which fosters wider collaboration and increased citations

- maximum visibility for your research: over $100 \mathrm{M}$ website views per year

At $\mathrm{BMC}$, research is always in progress.

Learn more biomedcentral.com/submissions 